\title{
ANATOMIA DO LENHO DE MACLURA TINCTORIA D. DON EX STEUD. ${ }^{1}$
}

\author{
PAULO FERNANDO DOS SANTOS MACHADO ${ }^{2}$ ANELISE MARTA SIEGLOCH ${ }^{3}$ \\ TALITA BALDIN ${ }^{4}$ RODRIGO COLDEBELLA $^{5}$ CRISTIANE PEDRAZZI $^{6}$ \\ JOSÉ NEWTON CARDOSO MARCHIORI ${ }^{7}$
}

\section{RESUMO}

O lenho de Maclura tinctoria é anatomicamente descrito e ilustrado com fotomicrografias, com base em material procedente de Porto Mauá, RS, Brasil. Na estrutura da madeira destacam-se: poros solitários, em sua maioria; placas de perfuração simples; elementos vasculares de comprimento médio; pontoações intervasculares alternas e ornamentadas; parênquima axial predominantemente vasicêntrico; raios homogêneos; fibras libriformes; tubos laticíferos; e cristais prismáticos.

Palavras-chave: Anatomia da madeira, Maclura tinctoria, Moraceae.

\section{ABSTRACT}

[Wood anatomy of Maclura tinctoria D. Don ex Steud.].

The wood of Maclura tinctoria is anatomically described and illustrated with photomicrographs, based on material collected in the municipality of Porto Mauá, Rio Grande do Sul State (Brazil). The anatomical structure presents: simple perforation plates; medium length vascular elements; alternate vestured pits; mostly vasicentric axial parenchyma; homogeneous rays; libriform fibers; laticifers tubes; and prismatics crystals. Key words: Wood anatomy, Maclura tinctoria, Moraceae.

\section{INTRODUÇÃO}

A família Moraceae inclui cerca de 50 gêneros e 1500 espécies, distribuídas, principalmente, nas regiões tropicais e subtropicais do mundo (Souza \& Lorenzi, 2012). Morfologicamente, a família é reconhecida

1 Recebido em 30-3-2015 e aceito para publicação em 20-5-2015.

2 Mestrando do Programa de Pós-Graduação em Engenharia Florestal. Bolsista CNPq. Universidade Federal de Santa Maria. Santa Maria, RS, Brasil. barcasole@gmail.com

3 Doutoranda do Programa de Pós-Graduação em Engenharia Florestal. Bolsista CAPES. Universidade Federal de Santa Maria. Santa Maria, RS, Brasil.

4 Doutoranda do Programa de Pós-Graduação em Engenharia Florestal. Bolsista CAPES. Universidade Federal de Santa Maria. Santa Maria, RS, Brasil..

5 Mestrando do Programa de Pós-Graduação em Engenharia Florestal. Bolsista CAPES. Universidade Federal de Santa Maria. Santa Maria, RS, Brasil.

6 Engenheira Florestal, Dra. Professora do Departamento de Ciências Florestais, Universidade Federal de Santa Maria. Santa Maria, RS, Brasil.

7 Engenheiro Florestal, Dr. Bolsista de Produtividade em Pesquisa (CNPq - Brasil). Professor Titular do Departamento de Ciências Florestais, Universidade Federal de Santa Maria. Santa Maria, RS, Brasil. pelas cicatrizes estipulares amplexicaules (Marchiori, 1997), bem como pelos ramos inermes ou com espinhos, latescentes e com estípulas visíveis no ápice, pelas folhas simples, alternas, de bordos inteiros ou recortados, pelas inflorescências de tipo sicônio (Ficus), racemo (Sorocea) ou espiga (Maclura), e pelos frutos do tipo aquênio (Ficus) ou drupa (Sobral et al., 2013).

No Brasil, ocorrem 18 gêneros e, aproximadamente, 200 espécies, em sua maioria da Amazônia, destacando-se o gênero Ficus pelas numerosas espécies distribuídas em quase todos os ecossistemas brasileiros (Souza \& Lorenzi, 2012).

O gênero Maclura presta homenagem ao geólogo americano William Maclure (1763 1840) e reúne cerca de 6 espécies americanas. Maclura tinctoria, objeto do presente estudo, é conhecida, popularmente, por "tajuva" (tatayba, em guarani) ou moral silvestre (Argentina, Paraguai), e sua madeira serve para pranchas e móveis, além de fornecer pigmento cor-de-fogo (Schulze-Hofer \& Marchiori, 2008).

A espécie distribui-se, naturalmente, do México ao sul do Brasil. No Rio Grande do Sul, 
é nativa na Floresta Atlântica, no Alto Uruguai e no rebordo da Serra Geral (Sobral et al., 2006). Trata-se de árvore de copa globosa ou umbeliforme, caducifólia, produtora de látex amarelado, e com espinhos ramificados no tronco (Marchiori, 1997). A madeira, dura e pesada $\left(0,84 \mathrm{a} 0,98 \mathrm{~g} / \mathrm{cm}^{3}\right)$, é recomendada para construções civis e navais, dormentes, parquetes e objetos torneados; devido à boa flexibilidade, indica-se, também, para cabos de ferramentas (Marchiori, 1997).

Com relação à anatomia do lenho, a família apresenta: poros pouco numerosos e predominantemente solitários, de diâmetro médio a grande; porosidade, não raro em anel; vasos extremamente curtos a médios, com espessamentos espiralados e placas de perfuração simples; pontoações intervasculares pequenas a grandes; pontoações raio-vasculares circulares ou transversalmente alongadas; parênquima paratraqueal, geralmente aliforme ou confluente, por vezes em faixas regulares; raios com 1 a 15 , mais comumente 3 a 6 células de largura, com escassos unisseriados; raios homogêneos até fracamente heterogêneos, marcadamente heterogêneos em poucas espécies, e com tubos laticíferos em muitos gêneros; e fibras de pontoações simples ou areoladas muito pequenas, frequentemente septadas, de tamanho moderadamente curto a médio (Metcalfe \& Chalk, 1972).

A madeira das Moráceas, segundo Marchiori (1997), é relativamente evoluída, incluindo placas de perfuração simples e parênquima tipicamente paratraqueal; os raios são homogêneos ou fracamente heterogêneos, com tubos laticíferos em espécies de Ficus e Maclura, e fibras de pontoações simples ou areoladas.

De acordo com Tortorelli (2009), a madeira de Maclura tinctoria apresenta: poros numerosos (16 a $28 / \mathrm{mm}^{2}$ ); solitários ou em curtos múltiplos radiais de 2-3, de forma oval ou elíptica, e com $100(60-150) \mu \mathrm{m}$ de diâmetro; elementos vasculares de 350-450 $\mu \mathrm{m}$ de comprimento; placas de perfuração simples, horizontais ou oblíquas ao vaso; pontoações intervasculares alternas, pequenas, com abertura interna linear, inclusa; parênquima aliforme, com tendência a unilateral e em faixas de 2 a 8 células de largura, raro vasicêntrico incompleto; séries parenquimáticas axiais de 2-4 (até 8) células; raios numerosos (5 a $8 / \mathrm{mm}$ ), uni a trisseriados, homogêneos, de células procumbentes, baixos (250 (100-400) $\mu \mathrm{m})$; fibras libriformes com pontoações simples, de paredes finas a espessas, e $970 \mu \mathrm{m}$ de comprimento médio; anéis de crescimento não demarcados.

O presente estudo, ao descrever a estrutura anatômica da madeira de Maclura tinctoria, visa à valorização desta essência florestal, ainda pouco conhecida no sul do Brasil.

\section{MATERIAL E MÉTODOS}

O presente estudo baseou-se em amostras do lenho de três indivíduos, provenientes de Porto Mauá, Rio Grande do Sul.

Para a confecção de lâminas histológicas foram extraídos três corpos de prova $(3 \times 3 \times$ $3 \mathrm{~cm}$ ) de cada uma das amostras, orientados para obtenção de cortes nos planos transversal (X), longitudinal radial (R) e longitudinal tangencial (T); um quarto bloquinho foi também preparado, com vistas à maceração.

O preparo de lâminas histológicas seguiu a metodologia descrita em Burger \& Richter (1991). A maceração foi realizada pelo método Ácido Nítrico-Acético (Barrichelo et al., 1983). Os cortes anatômicos foram tingidos com Safranina e Azul-de-Astra; o macerado, apenas com Safranina. A montagem de lâminas permanentes foi feita com Entellan.

A descrição microscópica baseou-se nas recomendações do IAWA Committee (Wheeler et al., 1989). No caso da percentagem dos tecidos, foram realizadas 600 determinações ao acaso, com auxílio de contador de laboratório, conforme proposto por Marchiori (1980). A abundância de poros foi obtida a partir de um quadrado de área conhecida, superposto a fotomicrografias de seções transversais da madeira. 
As medições foram realizadas em microscópio Carl Zeiss, no Laboratório de Anatomia da Madeira da Universidade Federal de Santa Maria. Nas características quantitativas, os números entre parênteses equivalem aos valores mínimos e máximos observados; o valor que acompanha a média é o desvio padrão As fotomicrografias foram tomadas em microscópio Leica DM 1000, equipado com câmera digital Olympus Camedia CX-40, no Laboratório de Anatomia da Madeira do Centro de Educação Superior Norte do Rio Grande do Sul (CESNORS/ UFSM), campus de Frederico Westphalen.

\section{DESCRIÇÃO ANATÔMICA}

Anéis de crescimento: fracamente delimitados por parênquima marginal e alargamento de células de radiais (Figura 1A,B).

Vasos: escassos a pouco numerosos $(5,6 \pm$ $2,7(2-9,5)$ poros $\left./ \mathrm{mm}^{2}\right)$, ocupando $12 \pm 4 \%$ do volume da madeira. Porosidade difusa. Poros solitários (74\%), em múltiplos radiais de 2-5 (24\%) e racemiformes (2\%), circulares ou ovais $(146 \pm 40(50-195) \mu \mathrm{m})$, em frequente contato com raios, e de paredes espessas $7 \pm 1,7$ (5 10) $\mu \mathrm{m}$ (Figura 1A,B). Elementos vasculares curtos $(259 \pm 50(120-330) \mu \mathrm{m})$, com placas de perfuração simples, oblíquas ou transversais ao vaso (Figura 1D,E). Apêndices, geralmente curtos $(25,6 \pm 16(10-50) \mu \mathrm{m})$, em uma extremidade. Pontoações intervasculares pequenas $(6,3 \pm 1,1(5,2-8,2) \mu \mathrm{m})$, alternas, circulares ou poligonais, ornamentadas, com abertura em fenda inclusa, frequentemente coalescente (Figura 1D,E). Pontoações raiovasculares, aparentemente simples, por vezes estendidas $(9 \pm 1,2(7,2-10,3) \mu \mathrm{m})$. Espessamentos espiralados, ausentes. Conteúdo, presente.

Parênquima axial: representando $8 \pm 3 \%$ do volume da madeira; em arranjo paratraqueal vasicêntrico, vasicêntrico incompleto, por vezes aliforme, aliforme confluente, paratraqueal escasso e em faixa marginal no limite do anel de crescimento (Figura 1A,B). Conteúdo, ausente. Séries parenquimáticas de $368 \pm 63$
(280 - 513) $\mu \mathrm{m}$ de altura, com 2 - 4 (até 7) células, (Figura 1C,D). Cristais romboédricos com 4-20 cristais por série (Figura 1F), também visualizados em seção transversal.

Raios: numerosos (6 $\pm 1,1(4-7)$ raios $/ \mathrm{mm})$, unisseriados (4\%), bisseriados (13\%), trisseriados $(45 \%)$ e tetrasseriados $(38 \%)$, representando $20 \pm 2,3 \%$ do volume da madeira. Tecido radial homogêneo, composto inteiramente de células procumbentes (Figura 1C,D). Os multisseriados, de $256 \pm 75$ (113 425) $\mu \mathrm{m}$ e 7 - 26 células de altura. Os unisseriados, de $87 \pm 36(38-175) \mu \mathrm{m}$ e $2-8$ células de altura. Raios agregados, células envolventes, células radiais de paredes disjuntas, células perfuradas e conteúdos, ausentes. Raios fusionados, cristais e tubos laticíferos, presentes (Figura 1F).

Fibras: libriformes, de comprimento médio $(980 \pm 110(750-1170) \mu \mathrm{m})$, com $12 \pm 1,9(7,5$ - 15) $\mu \mathrm{m}$ de largura, e paredes finas a espessas $(2,3 \pm 0,6(0,6-3,1) \mu \mathrm{m})$, ocupando $60 \pm 3,4 \%$ do volume da madeira (Figura 1A,B). Espessamentos espiralados, fibras septadas e traqueídeos, ausentes. Fibras gelatinosas, abundantes (Figura 1A,B).

Outros caracteres: variantes cambiais, canais intercelulares, células oleíferas, células mucilaginosas, estratificação, máculas medulares, ausentes. Cristais e tubos laticíferos, presentes (Figura 1F).

\section{ANÁLISE DA ESTRUTURA ANATÔMICA}

O lenho de Maclura tinctoria reúne as características anatômicas predominantes em Moraceae, de acordo com Metcalfe \& Chalk (1972): poros geralmente solitários, pouco numerosos, de diâmetro médio; placas de perfuração simples; pontoações intervasculares pequenas; pontoações raio-vasculares circulares ou transversalmente alongadas; parênquima paratraqueal; raios homogêneos; fibras libriformes de comprimento médio; e tubos lactíferos, presentes.

A espécie pode ser considerada evoluída, de acordo com Marchiori (1997), pois apresenta 


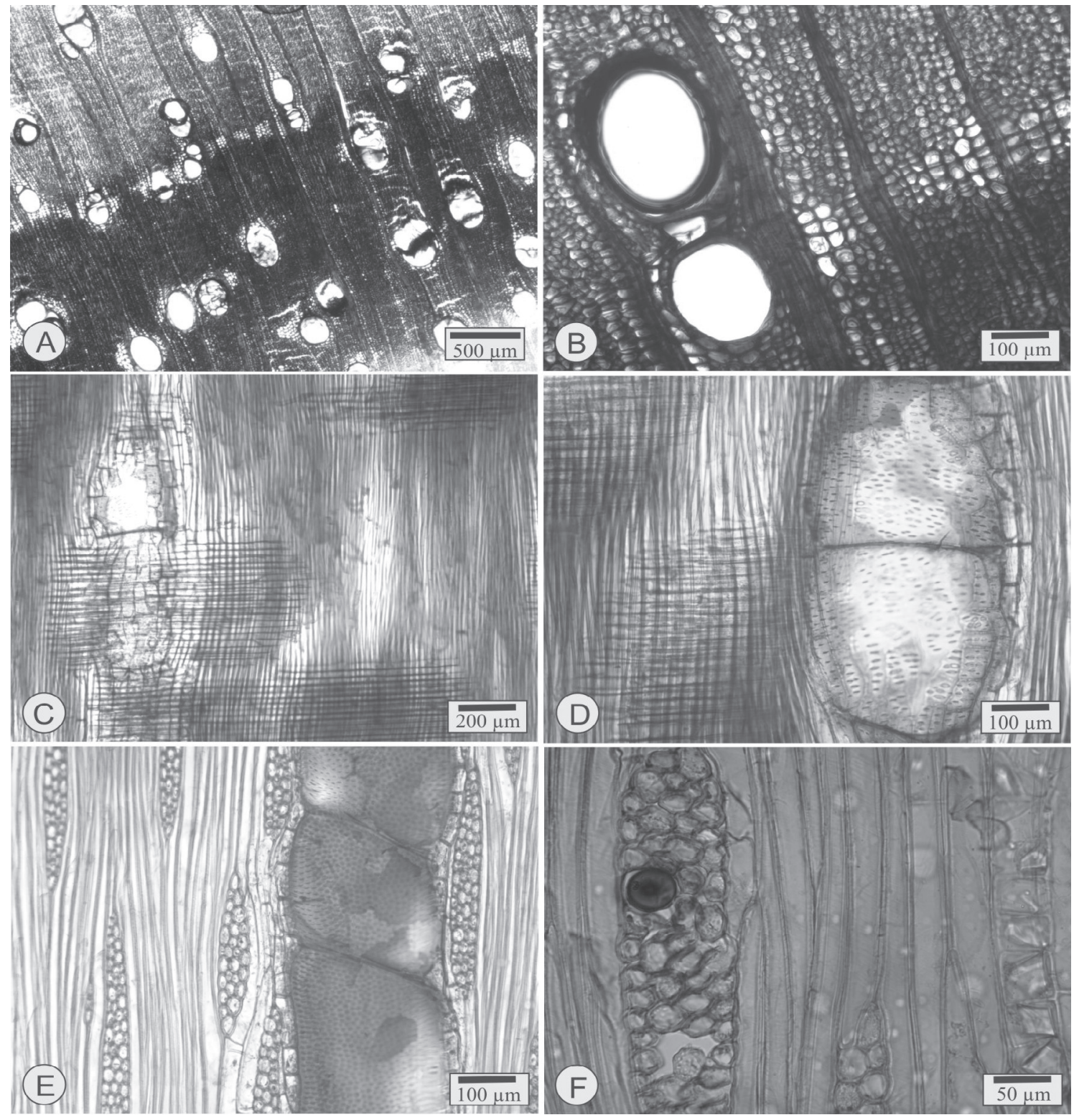

FIGURA 1 - Fotomicrografias do lenho de Maclura tinctoria. A-Parênquima marginal no limite de anel de crescimento, porosidade semi-difusa, poros solitários e em curtos múltiplos radiais, e parênquima vasicêntrico, por vezes confluente (seção transversal). B - Mesma seção, destacando o parênquima marginal e tênue alargamento de raios. C - Raios homogêneos, em seção radial, compostos inteiramente de células procumbentes. D - Células procumbentes de raio, e vaso com pontoações alternas e placa de perfuração transversal (seção radial). E - Raios multisseriados e vaso com placas de perfuração oblíquas. F - Raio tetrasseriado com tubo laticífero e séries cristalíferas no parênquima axial (seção tangencial). 
placas de perfuração simples, parênquima tipicamente paratraqueal, raios homogêneos e fibras libriformes.

A presente descrição corrobora Tortorelli (2009), ao constatar a presença de poros solitários e em curtos múltiplos de 2-3, ovais ou elípticos, de elementos vasculares de comprimento médio, pontoações intervasculares alternas, de parênquima axial com 2-4 (até 8) células de altura, de raios numerosos, homogêneos, com células cristalíferas, e de fibras libriformes de paredes finas a espessas.

Ao contrário desse autor, entretanto, observou-se, no material examinado a presença de anéis de crescimento fracamente distintos, delimitados por parênquima marginal e alargamento de raios no limite do anel; predominância de parênquima vasicêntrico e aliforme, de raios tetrasseriados e a presença de tubos laticíferos. O último caráter também é confirmado por Metcalfe \& Chalk (1972) e Marchiori (1997) para o gênero e espécie em estudo, respectivamente.

Para o gênero Maclura, Record \& Hess (1949), citam, ainda: porosidade em anel, poros agrupados no lenho tardio, tiloses, elementos vasculares com espessamentos espiralados; pontoações intervasculares alternas coalescentes, parênquima tipicamente vasicêntrico; e presença de fibras gelatinosas.

\section{REFERÊNCIAS BIBLIOGRÁFICAS}

BURGER, L.M.; RICHTER, H.G. Anatomia da Madeira. São Paulo: Ed. Nobel, 1991. 154 p.

BARRICHELO, L.E.G.; FOELKEL, C.E.B. Processo nítrico-acético para maceração de madeira. Silvicultura, n. 28, p. 732-733, 1983.
MARCHIORI, J.N.C. Estudo anatômico do xilema secundário e da casca de algumas espécies dos gêneros Acacia e Mimosa, nativas no Estado do Rio Grande do Sul. Curitiba: UFPR, 1980. 186 f. Dissertação de Mestrado (Curso de PósGraduação em Engenharia Florestal).

MARCHIORI, J.N.C. Anatomia da madeira e casca do maricá, Mimosa bimucronata (DC.) O. Kuntze. Ciência Florestal, Santa Maria, v. 3, n. 1, p. 85-106, 1993.

MARCHIORI, J.N.C. Dendrologia das Angiospermas: das Magnoliáceas às Flacurtiáceas. Santa Maria: Editora UFSM, 1997. $271 \mathrm{p}$.

METCALFE, C.R.; CHALK, L. Anatomy of the Dicotyledons. Oxford: Clarendon Press, 1972. p. 476-487.

RECORD, S.J.; HESS, R.W. Timbers of the New World. New Haven: Yale University Press, 1949. $640 \mathrm{p}$.

SOBRAL, M.; JARENKOW, J.A.; BRACK, P.; IRGANG, B.; LAROCCA, J.; RODRIGUES, R.S. Flora arbórea e arborescente do Rio Grande do Sul, Brasil. São Carlos: RiMA: Novo Ambiente, 2006. 350p.

SOUZA, V.C.; LORENZI, H. Botânica Sistemática: guia ilustrado para identificação das famílias de Fanerógamas nativas e exóticas no Brasil, baseado em APG III. Nova Odessa: Instituto Plantarum, 2012. 768 p.

SCHULZE-HOFER, M.C.; MARCHIORI, J.N.C. $O$ uso da madeira nas reduções jesuítico-guarani do Rio Grande do Sul. Porto Alegre: IPHAN, 2008. 80p.

TORTORELLI, L. A. Maderas e bosques argentinos. Buenos Aires: Orientación Gráfica Editora, 2009. $576 \mathrm{p}$.

WHEELER, E.A.; BAAS, P.; GASSON, P.E. IAWA list of microscopic features for Hardwood identification. IAWA Bulletin 